\title{
Critical care management in burns: a review of current evidence and guidelines - Part 2
}

\author{
Umesh Jayarajah, Oshan Basnayake, Gayan Ekanayake \\ Department of Plastic and Reconstructive Surgery, National Hospital of Sri Lanka, Colombo, Sri Lanka
}

Keywords: Burns; severe burns; critical care; burns resuscitation; fluid resuscitation

\begin{abstract}
Recent literature on the management of critically ill patients has altered the beliefs and clinical behaviours, questioning many dogmas that were practised without much evidence. The critical care in a severely burn-injured patient requires special attention in resuscitation, haemodynamic monitoring, management of complications, organ support and determinants of outcome. The goal of resuscitation is to maintain intravascular volume and tone while correcting the reversible changes in altered physiology, aided by early debridement of burned tissue and elimination of the source of physiological derangement. Practitioners should target resuscitation based on goal-directed therapy using noninvasive markers of cardiac output. The management requires the input of a multi-disciplinary team to achieve critical care and early surgical intervention and management of complications and organ support.
\end{abstract}

\section{Introduction}

Recent literature on the management of critically ill patients has altered the beliefs and clinical behaviours, questioning many dogmas that were practised without much evidence [1]. Furthermore, the fundamental understanding of critical care in terms of fluid management, haemodynamic monitoring, management of acute respiratory distress syndrome (ARDS), organ support and nutrition support are changing [1,2]. The goal of resuscitation is to maintain intravascular volume and tone while correcting the reversible changes in altered physiology, aided by early debridement of burned tissue and elimination of the source of physiological derangement. The definition of severe burns is based on the surface area $(20 \%$ excluding superficial burns), presence of inhalational or electrical injury, patients' age and comorbidities [3]. The critical period in burns is usually transient, lasting for a few days. However, may include intermittent episodes of deterioration based on burning related complications. This

Correspondence: Gayan Ekanayake

E-mail: gayanse2003@yahoo.com

(iD) https://orcid.org/0000-0001-8420-7073

Received: 11-01-2020 Accepted: 05-11-2020

DOI: http://doi.org/10.4038/sljs.v38i3.8788

The Sri Lanka Journal of Surgery 2020; 38(3): 38-45 review focuses on the contemporary literature on the critical care of severe burns once the patient has been stabilised after the initial injury. The review consists of two parts and the first part focusses on fluid resuscitation, goal-directed fluid therapy, haemodynamic monitoring and coagulopathy in severe burns [4]. The second part describes aspects such as thromboprophylaxis, the role of suppressing hypermetabolism, glycaemic control, nutritional support, sepsis and infection control, management of inhalational injuries, surgical debridement, pain management and palliative care in severe burns.

\section{Methods}

We performed a literature search on PubMed and Google Scholar and looked for published original articles, review articles and guidelines on critical care management in burns, up to November 2019. Our search was limited to articles in English. Correspondence, dissertations and unpublished materials were not considered. The information was summarised and presented qualitatively (narratively) under subheadings.

\section{Contents:}

Fluid resuscitation in severe burns

Goal-directed fluid therapy and Haemodynamic monitoring

Evidence on the choice of fluid for resuscitation

Management of coagulopathy in severe burns

Thromboprophylaxis in burns

The role of suppressing hypermetabolism in severe burns

Glycaemic control in severe burns

Nutritional support in severe burns

Sepsis and infection control in burns

Management of inhalational injuries and acute respiratory distress syndrome (ARDS)

Early surgical debridement and soft tissue cover

Pain management in severe burns

Palliative care in severe burns

Conclusion 


\section{Thromboprophylaxis in burns}

Deep vein thrombosis (DVT) and associated embolic events play a major role in burn patients' morbidity and mortality. A nationwide study including 36,638 burn patients showed a DVT rate of $0.8 \%$ with identifiable risk factors such as more than $20 \%$ burn surface area, old age, use of blood and blood products, mechanical ventilation and previous similar events [5]. Prophylactic use of heparin has shown benefit in thromboprophylaxis in burn patients [6]. Although prophylactic treatment is indicated, the need for surgical interventions such as burn wound excision and grafting may limit the use of pharmacological agents. There are controversies regarding the dosage of these agents because of burn associated hypermetabolism and fluid shifts which may alter the volume distribution. Apart from pharmacological agents, measures such as compression devices, early mobilization and physiotherapy are helpful in the prevention ofDVT [5].

\section{The role of suppressing hypermetabolism in severe burns}

Hypermetabolic response or metabolic response to trauma is a recognized entity in all types of trauma. The magnitude and the duration of the hypermetabolic response in burn patients differ from other types of trauma [7]. Various stimuli such as burn wounds, pain, thermal changes, and hypovolemia act as triggers for a hypermetabolic response. These result in the activation of the sympathoadrenal and hypothalamicpituitary-adrenal axes triggering a cascade of catabolic processes [7]. The response is evident by increased blood pressure, heart rate, temperature, and protein and lipid catabolism. The hypermetabolic response is categorised as the ebb phase and flow phase. Initial decreased cardiac output, temperature and metabolic rate are seen in the ebb phase. A gradual increase in the metabolic activity is characterized in the flow phase which is observed after $48 \mathrm{hrs}$ of burn injury. The duration of this phase is variable and may last even years after the initial insult [8]. The intensity of the response correlates with the burn surface area above 15 percent and is almost always associated when the area exceeds 40 percent [7]. Early recognition and treatment are important in the improvement of the overall outcome of the burn patients [9]. In the treatment process, attenuation of the metabolic response can be achieved by minimizing the stimuli and modulating the response. Initial adequate fluid resuscitation for tissue perfusion, pain management, prevention of hypothermia and proper timely nutritional support has shown to minimize the stimuli for a metabolic response. A meta-analysis has shown that early excision of burn and grafting is an important strategy to minimize the stimuli for metabolic response [10]. It also prevents the risk of associated infectious complications of burn wounds. For the modulation of the hypermetabolic response, several pharmacological agents have been studied. A systematic review of 15 randomised trials had shown that anabolic steroids like oxandrolone were beneficial in the modulation of protein catabolism and improving wound healing in burns over 20 percent burn surface area [11].

Significant lowering of insulin-like growth factor-1 (IGF-1) is associated with severe burn injury and its replacement is proven to be associated with better outcomes [12]. Replacement of IGF-1 reduces gut atrophy and bacterial translocation after severe burns. Furthermore, the hypermetabolic response is modulated and protein catabolism is reduced while augmenting anabolic response [12] Moreover, it improves immune function while decreasing the inflammatory response due to severe burns. Therefore, considerable emphasis is being given to the utility of IGF-1 in the management of severe burns [12]. Beta-blockers such as propranolol cause blunting of effects of increased catecholamines have also used in burn patients [13].

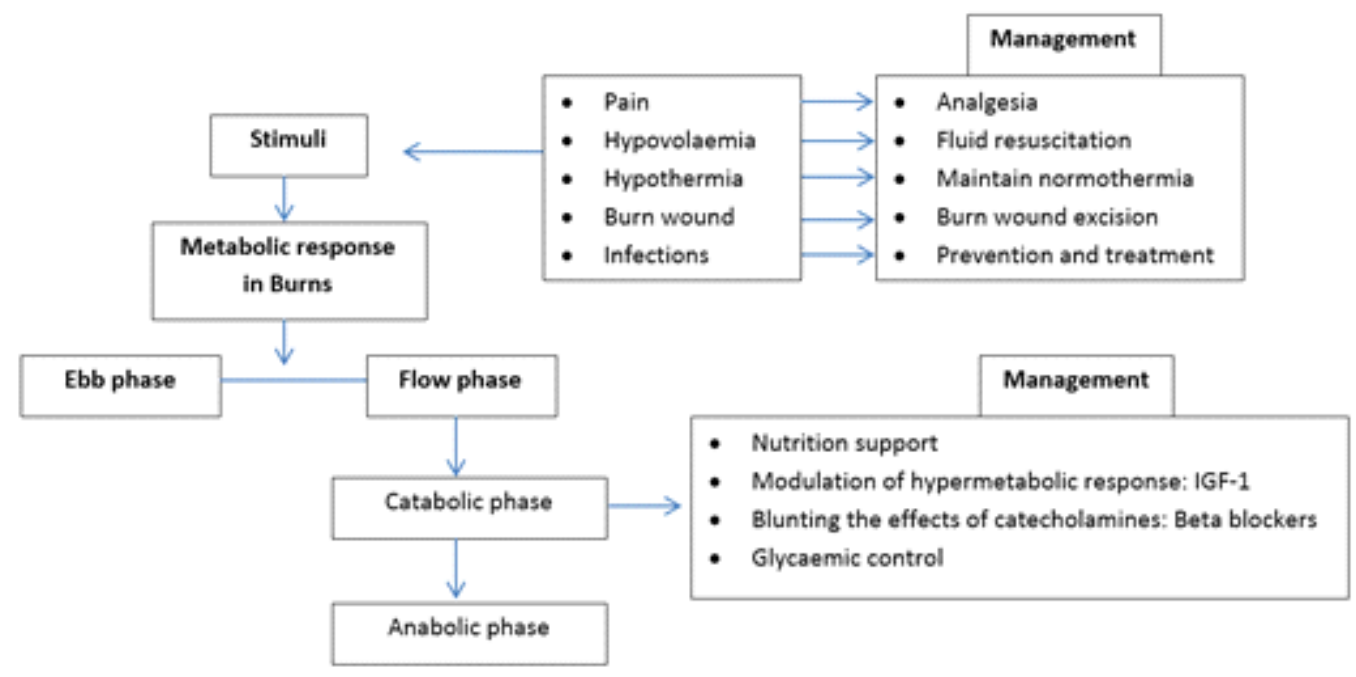

Figure 1. Modulating hypermetabolism in severe burns 
Management of hypermetabolic response is multimodal and early recognition and treatment improve the outcome (Figure 1).

\section{Glycaemic control in severe burns}

Glycaemic control plays a crucial role in burns to minimize the hypermetabolism and provide adequate nutrition for recovery process following burns. Because of the burn associated stress response, there is increased catabolism as well as peripheral insulin resistance causing an increase in the blood glucose level. Blood glucose potentiates the inflammatory response of the hypermetabolic state by oxidative stress and insulin provides counter inflammatory effect by minimizing macronutrients induced inflammation [14]. Insulin also increases muscle protein synthesis and thereby improves the wound healing at the donor site and lean body mass in burn patients [15]. A reduction in post-burn infection and related mortality was also noted [16].

Similar to another critically ill patient, maintenance of glycaemic control in the desired range is important in burn patients. Although the exact range is uncertain, a systematic review on the effectiveness and safety of intensive insulin treatment and secretagogues showed that a moderate control of glucose level $(130-150 \mathrm{mg} / \mathrm{dL})$ in adults was beneficial [17]. The above-mentioned control was achieved by the continuous insulin infusions but such management inward setting may be difficult because of the need for intermittent fasting for multiple surgical procedures and the workload [9]. Therefore, the desired range of less than $180 \mathrm{mg} / \mathrm{dl}$ with avoidance of hypoglycaemic episodes is recommended in the ward setting [18].

\section{Nutritional support in severe burns}

Nutritional support is essential for the burn patients because of the hypermetabolic state and increased demand for nutrients. Individual factors such as moderate to severe burns more than 10-20 percent depending on the age, patients with inhalational injury and obesity are recognized as indications for nutritional support $[19,20]$. Therefore, most patients with severe burns would require nutrition support. Although there are no specific guidelines on burns nutrition, the expert consensus of American Society for Parenteral and Enteral Nutrition (ASPEN) guidelines advise for early initiation of enteral feeding in burn patients [21]. It was observed that enteral nutrition was associated with fewer infections and lesser metabolic derangements in burn patients compared with parenteral [22]. However, haemodynamic status should also be considered because of mesenteric ischemia associated ileus may hinder the tolerance of enteral feeding.

Concerning enteral nutrition in critically ill patients, there is an on-going debate about gastric versus postpyloric feeding.
Factors for gastric feeding are the easy placement of the tube, the achievement of gastric decompression and reduced diarrhoeal episodes but gastric stasis and risk of aspiration are associated complications. However, a meta-analysis in critically ill patients (not specific to burns) showed similar outcomes between gastric and post-gastric feeling in terms of mortality but with increased risk of aspiration pneumonia associated with gastric feeding [23]. Such evidence on the type of enteral feeding is limited among severe burns patients.

Although there are many different methods to calculate the nutrition requirement, Curreri formula is one accepted worldwide which considers weight, burned surface area and age. In addition to the calorie requirement, micronutrients and electrolytes should also be considered. Modification of this enteral nutrition with immune nutrition is also considered. Glutamine has a proven beneficial in burn patients for the lower rates of gram-negative bacteraemia and reduction inhospital mortality rates [24].

The exact timing of discontinuation is variable because of the flow phase of hypermetabolic response may last years after the insult. Therefore, individual decisions should be made considering the anthropometric measurements such as weight, clinical and biochemical evidence of nutritional deficiency which may suggest the need for prolonging supplementation [25].

\section{Sepsis and infection control in burns}

Burn injury-related damage and secondary consequences of physiological derangement with altered immunity cause increased susceptibility for infections [26]. Infection-related morbidity and mortality remain a major problem in managing burn patients. Causes for infection may be broadly categorized in to burn wound infection and other infections. Non-burn wound-related infections are common due to the hypermetabolic response and the altered immune mechanisms. Inhalational injury, chest burns and inadequate ventilation increase susceptibility for pneumonia [26]. Invasive monitoring devices such as urinary, arterial and venous catheters act as portals of entry for infections. Loss of barrier function of the skin after burns facilitate the entry of the organisms and loss of commensal flora causes an overgrowth of invasive pathogens[26]. Avascular necrotic protein-rich material also acts as a good culture medium for bacterial growth. Type of organism depends on the timing of infection, location and patterns of microbial infections in the local setting. Due to the pathophysiological alterations in burns, conventional clinical features of infection and sepsis such as hyperthermia, tachycardia and hypotension are unreliable [26]. A high index of suspicion to identify features of infection and identification of source is the key step in management. Newly developing feeding intolerance can be 
taken as a surrogate marker of probable infection [26]. Changes in the wound integrity, degree of involvement, loss of skin grafts and local features of inflammation may suggest burn wound infection. Depending on the degree of microbial invasion, colonization, non-invasive or invasive infections may result. This eventually leads to burns sepsis and organ dysfunction when it is coupled with the systemic inflammatory response in burns.

Infections may be confirmed by the histopathological evaluation and microbial cultures with a bacterial count $>105$ bacteria per gram of tissue[26]. Other markers such as leucocytosis, leukopenia, thrombocytopenia, and elevated acute phase reactant like $\mathrm{C}$-reactive proteins may be also observed. However, the specificity is very limited due to the concomitant systemic inflammatory response in burns. Procalcitonin as a maker of infection was also studied in a meta-analysis of burn patients and cut off value of 0.53-3 $\mathrm{ng} / \mathrm{ml}$ was determined with widely variable sensitivity and specificity [27]. Lactate level is essential in the diagnosis and monitoring in burns sepsis and is an important early predictor of morbidity and mortality [28]. Early burn wound excision and coverage is a proven strategy for prevention of burn wound infection and management. Empirical antibiotic treatment after obtaining appropriate cultures from the clinically suspected source of infection and later deescalation of treatment depending on the culture and sensitivity pattern is compulsory in the treatment of infections. A systematic review which analysed evidence between 1996 to 2016 revealed no benefit in prophylactic antibiotics for prevention of burn wound infection prevention other than burn wound excision and burn reconstruction procedures [29]. Preventive strategies include hand hygiene, prevention of faecal and urinary soiling [26].

\section{Management of inhalational injuries and acute respiratory distress syndrome (ARDS)}

Compromised breathing and ventilation are associated with burn injury. Inhalational injury-related changes in the airways and lungs, acute respiratory distress syndrome (ARDS), systemic chemical effects such as carbon monoxide poisoning are recognized causes of hypoxemia (Figure 2). Reduced level of consciousness and full thickness circumferential chest burns may also cause impaired ventilation. Furthermore, full thickness abdominal burns may result in abdominal compartment syndrome and restrict the diaphragmatic movement resulting in impaired ventilation. Elective early intubation and securing the airway is important in patients with inhalational injury to prevent delayed complications and before transfer [30].

The place for bronchoscopy and broncho-alveolar lavage in the diagnosis and treatment of inhalational injury was also studied [31, 32]. Bronchoscopy allows visualization of the upper airway and proximal parts of lower airways and may be useful in suctioning of debris. Studies have shown the correlation between bronchoscopy classification of severity of the inhalational injury and in-hospital mortality and duration of the mechanical ventilation[31]. In severe subglottic inhalational injuries, bronchoscopy and pulmonary

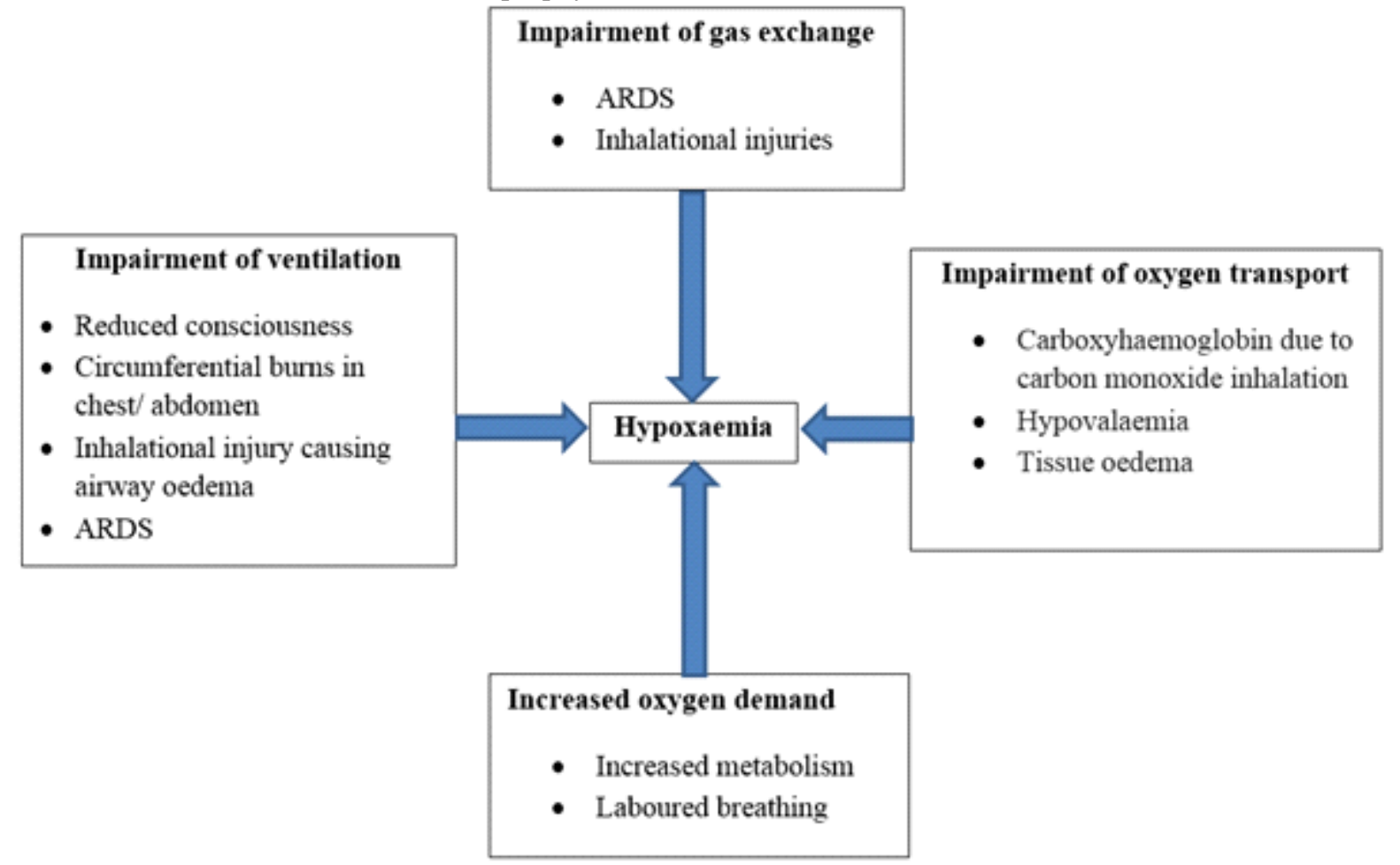

Figure 2. Mechanisms causing hypoxaemia following burns 
toileting and nebulization using fibrinolytic and mucolytics were shown to be beneficial [32].

ARDS is a recognized complication with high mortality in burns. It is either due to the direct insult from inhalational injury or secondary to systemic hypermetabolic or inflammatory response. Burn patients with ARDS are managed with intubation and ventilation. According to the ARDS network study, lung protective ventilator strategies such as low tidal volumes, limited plateau pressures to prevent barotrauma have significantly improved outcomes [33]. However, patient with inhalational injury was excluded from this study. Some studies showed higher tidal volumes in ARDS treatment in paediatric burns patient showing better outcome but exact tidal volumes in burns are yet to determine [33]. The patient specific decision on the lowest tolerated tidal volumes and plateau pressures is advisable in burn patients. Other supportive treatment modalities like bronchodilators, mucolytic and chest physiotherapy can be administered [34].

Furthermore, a review of 56 studies showed benefits in bronchoscopy and pulmonary toileting, permissive hypercapnia and heparin nebulization as treatment modalities[32].

\section{Early surgical treatment and soft tissue cover}

Early surgical burn wound excision or debridement is an essential component in the initial burns resuscitation [35]. This is because the deep burn wounds are key in the pathogenesis of systemic inflammatory response syndrome and require early removal to aid in recovery [36]. The advances in burn injury pathophysiology, critical care, pharmacological interventions and organ support has improved survival and an increasing number of severe burns patients survive the initial injury. Therefore, the aspects in surgical care have shifted from achieving mere survival to rapid wound closure, scar quality, functional outcome and cosmesis [35].

The severely burned patients usually have burns of varying depth, each requiring different management approaches. Superficial burn wounds which include superficial epidermal and superficial partial thickness wounds do not require excision. Surgical scrub and covering the wound with a suitable dressing would suffice [36]. Deep burn wounds which include deep partial thickness and full thickness burns require early burn wound excision [36]. Burn wound debridement and coverage are done in the operating room once the patient has been haemodynamically stabilised generally within 24 to 72 hours following the injury [36]. The period required for full excision and burn coverage may depend on the extent of injury [36]. For burns with larger burn surface area techniques to achieve wound, the cover may include skin graft with wide meshing, temporary coverage using xenografts or allografts, donor site re-harvesting and the use of skin substitutes [36,37].

Due to the limitations in skin grafting in severe burn patient such as poor healing and scarring of donor sites due to repeated harvesting, alternative strategies were developed to replace autograft [38]. The xenograft and allograft using cadaveric skin graft may be useful in the initial period as the immunity is low in the critically ill burns patient. However, with recovery, patients regain the immunity resulting in rejection, requiring repeated autografts. This lead to further research and development of biodegradable materials as temporary skin cover and composite cultured skin [38]. These have shown promising results in a selected group of burns patients. Further large scale studies are needed before incorporating into routine practice. However, the high cost limits its use in developing countries with limited resources.

\section{Pain management in severe burns}

Good pain control is essential for the comprehensive burn care from initial insult to long term recovery. However, the control of pain may be challenging for the treating physician. The pain related to burns is classified as background pain and procedural pain [39]. The treatments for burn wounds may cause considerable procedural pain than the initial insult itself [37]. The pathophysiological mechanisms can be classified as nociceptive pain, neuropathic pain and pain due to psychosocial distress (Figure 3). Therefore, a multimodal approach is needed to approach burn pain. Objective pain assessment, understanding of pathophysiology, multi-modal pharmacological interventions with opioids as the mainstay and compassionate attention to psychosocial contributors to pain such as anxiety are required for pain management [39]. Better outcomes in healing and rehabilitation are associated with good pain control in burns [37].

Mild analgesics that show a ceiling effect in the doseresponse relationship such as acetaminophen and NSAIDs are usually not suitable for severe burns [40]. Ketamine is useful in severe burns due to its potential advantages in anaesthesia such as haemodynamic stability, preserving airway patency and hypercapnic and hypoxic physiological responses [40]. Management of anxiety with the use of anxiolytic agents in addition to opioids is useful in severe burns. Benzodiazepines in conjunction with opioids are associated with better control of background as well as procedural pain [40]. There is increasing evidence of the effectiveness in novel non-pharmacological techniques such as cognitive behavioural therapy, hypnosis and distraction techniques in burns, with specific emphasis on the reduction of procedural pain and anxiety [41]. 


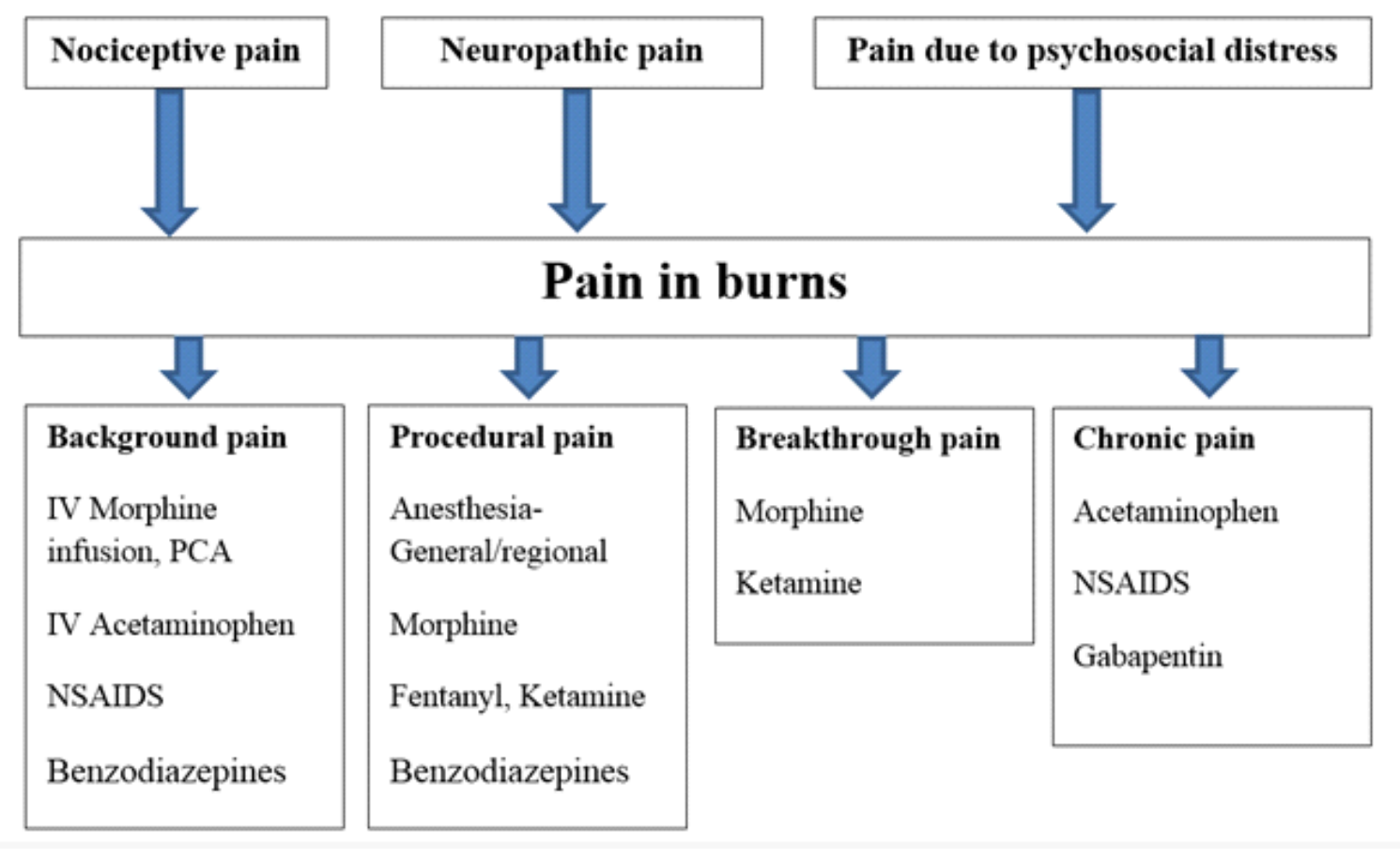

Figure 3. Mechanisms and types of pain in burns

\section{Palliative care in severe burns}

Despite the advancements in the approach to burns management, severe burns carry increased mortality. In some cases, the futility of treatment may have to be considered and discussed early by a multi-disciplinary team. Involvement of the palliative care specialists should be included if feasible to provide patient comfort and end-of-life support [37]. The protocols for the selection of patients for palliative care should be institution-specific based on the sound clinical judgement if salvage is possible depending on burn related factors and patients' comorbidities.

\section{Conclusion}

Inappropriate resuscitation may be common among burns patients. Practitioners should target resuscitation based on goal-directed therapy using non-invasive markers of cardiac output. The pathophysiological mechanisms and the definition of systemic inflammatory response syndrome (SIRS) and sepsis are different in the burns patient.

All authors disclose no conflict of interest. The study was conducted in accordance with the ethical standards of the relevant institutional or national ethics committee and the Helsinki Declaration of 1975, as revised in 2000 .

\section{References}

1. Lavrentieva A: Critical care of burn patients. New approaches to old problems. Burns 2016, 42(1):13-19. https://doi.org/10.1016/j.burns.2015.04.009

2. Guilabert P, Usúa G, Martín N, Abarca L, Barret J, Colomina M: Fluid resuscitation management in patients with burns: update. BJA: British Journal of Anaesthesia 2016, 117(3):284-296. https://doi.org/10.1093/bja/aew266

3. Pham TN, Cancio LC, Gibran NS: American Burn Association practice guidelines burn shock resuscitation. Journal of Burn Care \& Research 2008, 29(1):257-266.

https://doi.org/10.1097/BCR.0b013e31815f3876

4. Jayarajah U, Basnayake O, Ekanayake G: Critical care management in burns: A review of current evidence and guidelines-Part 1. Sri Lanka Journal of Surgery. 2020;38(2):50-6. DOI: http://doi.org/10.4038/sljs.v38i2.8664

5. Satahoo SS, Parikh PP, Naranjo D, Davis JS, Duncan RC, Pizano LR, Namias N, Schulman CI: Are burn patients really at risk for thrombotic events? Journal of Burn Care \& Research 2015, 36(1):100-104.

https://doi.org/10.1097/BCR.0000000000000093

6. Geerts WH, Bergqvist D, Pineo GF, Heit JA, Samama CM, Lassen MR, Colwell CW: Prevention of venous thromboembolism: American College of Chest Physicians evidence-based clinical practice guidelines. Chest 2008, 133(6):381S-453S. https://doi.org/10.1378/chest.08-0656

7. Jeschke MG, Barrow RE, Herndon DN: Extended hypermetabolic response of the liver in severely burned pediatric patients. Archives of Surgery 2004, 139(6):641-647.

https://doi.org/10.1001/archsurg.139.6.641 
8. Gauglitz GG, Herndon DN, Kulp GA, Meyer III WJ, Jeschke MG: Abnormal insulin sensitivity persists up to three years in pediatric patients post-burn. The Journal of Clinical Endocrinology \& Metabolism 2009, 94(5):1656-1664. https://doi.org/10.1210/jc.2008-1947

9. Herndon DN, Tompkins RG: Support of the metabolic response to burn injury. The Lancet 2004, 363(9424):1895-1902. https://doi.org/10.1016/S0140-6736(04)16360-5

10. Ong YS, Samuel M, Song C: Meta-analysis of early excision of burns. Burns 2006, 32(2):145-150. https://doi.org/10.1016/j.burns.2005.09.005

11. Li H, Guo Y, Yang Z, Roy M, Guo Q: The efficacy and safety of oxandrolone treatment for patients with severe burns: a systematic review and meta-analysis. Burns 2016, 42(4):717727. https://doi.org/10.1016/j.burns.2015.08.023

12.Williams FN, Herndon DN, Jeschke MG: The hypermetabolic response to burn injury and interventions to modify this response. Clin Plast Surg 2009, 36(4):583-596. https://doi.org/10.1016/j.cps.2009.05.001

13.Flores O, Stockton K, Roberts JA, Muller MJ, Paratz JD: The efficacy and safety of adrenergic blockade after burn injury: a systematic review and meta-analysis. Journal of Trauma and Acute Care Surgery 2016,80(1):146-155. https://doi.org/10.1097/TA.0000000000000887

14.Dandona P, Chaudhuri A, Mohanty P, Ghanim H: Antiinflammatory effects of insulin. Current opinion in clinical nutrition and metabolic care 2007, 10(4):511-517.

https://doi.org/10.1097/MCO.0b013e3281e38774

15. Thomas S, Morimoto K, Herndon D, Ferrando A, Wolfe R, Klein G, Wolf S: The effect of prolonged euglycemic hyperinsulinemia on lean body mass after severe burn. Surgery 2002, 132(2):341347. https://doi.org/10.1067/msy.2002.126871

16.Jeschke MG, Kulp GA, Kraft R, Finnerty CC, Mlcak R, Lee JO, Herndon DN: Intensive insulin therapy in severely burned pediatric patients: a prospective randomized trial. American journal of respiratory and critical care medicine 2010, 182(3):351-359.

https://doi.org/10.1164/rccm.201002-01900C

17.Campbell JM, Adanichkin N, Kurmis R, Munn Z: Intensive insulin therapy, insulin sensitisers and insulin secretagogues for burns: A systematic review of effectiveness and safety. Burns 2018, 44(6):1377-1394.

https://doi.org/10.1016/j.burns.2017.09.013

18.Investigators N-SS: Intensive versus conventional glucose control in critically ill patients. New England Journal of Medicine 2009, 360(13):1283-1297.

https://doi.org/10.1056/NEJMoa0810625

19.Rousseau A-F, Losser M-R, Ichai C, Berger MM: ESPEN endorsed recommendations: nutritional therapy in major burns. Clinical nutrition 2013, 32(4):497-502.

https://doi.org/10.1016/j.clnu.2013.02.012

20. Demling RH: The incidence and impact of pre-existing protein energy malnutrition on outcome in the elderly burn patient population. The Journal of burn care \& rehabilitation 2005 , 26(1):94-100.

https://doi.org/10.1097/01.BCR.0000150302.71007.80
21.McClave SA, Taylor BE, Martindale RG, Warren MM, Johnson DR, Braunschweig C, McCarthy MS, Davanos E, Rice TW, Cresci GA: Guidelines for the provision and assessment of nutrition support therapy in the adult critically ill patient: Society of Critical Care Medicine (SCCM) and American Society for Parenteral and Enteral Nutrition (ASPEN). Journal of Parenteral and Enteral Nutrition 2016, 40(2):159-211.

https://doi.org/10.1177/0148607115621863

22.Lam NN, Tien NG, Khoa CM: Early enteral feeding for burned patients-an effective method which should be encouraged in developing countries. Burns 2008, 34(2):192-196.

https://doi.org/10.1016/j.burns.2007.03.010

23.Adam MD, Rupinder D, Andrew GD, Emma JR, Andrew RD, Daren KH: Comparisons between intragastric and small intestinal delivery of enteral nutrition in the critically ill: a systematic review and meta-analysis. Critical Care 2013, 17(3):R125. https://doi.org/10.1186/cc12800

24.Lin JJ, Chung XJ, Yang CY, Lau HL: A meta-analysis of trials using the intention to treat principle for glutamine supplementation in critically ill patients with burn. Burns 2013, 39(4):565-570. https://doi.org/10.1016/j.burns.2012.11.008

25.Barrett LW,Fear VS, Waithman JC,Wood FM,Fear MW: Understanding acute burn injury as a chronic disease. Burns \& trauma 2019, 7(1):23. https://doi.org/10.1186/s41038-019-0163-2

26.Sepsis ABACCoB, Group I, Greenhalgh DG, Saffle JR, Holmes IV JH, Gamelli RL, Palmieri TL, Horton JW, Tompkins RG, Traber DL et al: American Burn Association consensus conference to define sepsis and infection in burns. Journal of burn care \& research 2007, 28(6):776-790.

https://doi.org/10.1097/BCR.0b013e3181599bc9

27.Ren H, Li Y, Han C, Hu H: Serum procalcitonin as a diagnostic biomarker for sepsis in burned patients: a meta-analysis. Burns 2015, 41(3):502-509.

https://doi.org/10.1016/j.burns.2014.08.019

28.Kamolz L-P, Andel H, Schramm W, Meissl G, Herndon D, Frey M: Lactate: early predictor of morbidity and mortality in patients with severe burns. Burns 2005, 31(8):986-990.

https://doi.org/10.1016/j.burns.2005.06.019

29.Kalaria SS, Boonipat T, Smith JM, Cole EL: Antibiotic prophylaxis: current recommendations in plastic surgery. European Journal of Plastic Surgery 2019:1-8. https://doi.org/10.1007/s00238-018-1492-2

30.Mlcak RP, Jeschke MG, Mandel J, Finlay G: Inhalation injury from heat, smoke, or chemical irritants. Up To Date 2016: 12016 , 90.

31.Aung M, Garner D, Pacquola M, Rosenblum S, McClure J, Cleland H, Pilcher D: The use of a simple three-level bronchoscopic assessment of inhalation injury to predict inhospital mortality and duration of mechanical ventilation in patients with burns. Anaesthesia and intensive care 2018, 46(1):67-73. https://doi.org/10.1177/0310057X1804600110

32. Deutsch C, Tan A, Smailes S, Dziewulski P: The diagnosis and management of inhalation injury: An evidence based approach. Burns 2018, 44(5):1040-1051. https://doi.org/10.1016/j.burns.2017.11.013 
33. Sousse LE, Herndon DN, Andersen CR, Ali A, Benjamin NC, Granchi T, Suman OE, Mlcak RP: High tidal volume decreases adult respiratory distress syndrome, atelectasis, and ventilator days compared with low tidal volume in pediatric burned patients with inhalation injury. Journal of the American College of Surgeons 2015, 220(4):570-578. https://doi.org/10.1016/j.jamcollsurg.2014.12.028

34.Al-Mousawi AM, Mecott-Rivera GA, Jeschke MG, Herndon DN: Burn teams and burn centers: the importance of a comprehensive team approach to burn care. Clinics in plastic surgery 2009, 36(4):547-554.

https://doi.org/10.1016/j.cps.2009.05.015

35. White CE, Renz EM: Advances in surgical care: management of severe burn injury. Critical care medicine 2008, 36(7):S318S324. https://doi.org/10.1097/CCM.0b013e31817e2d64

36.Calota DR, Nitescu C, Florescu IP, Lascar I: Surgical management of extensive burns treatment using allografts. Journal of medicine and life 2012, 5(4):486-490.
https://www.ncbi.nlm.nih.gov/pmc/articles/PMC3539833/

37.Clarey A, Trainor D: Critical care management of severe burns and inhalational injury. Anaesthesia \& Intensive Care Medicine 2017, 18(8):395-400.

https://doi.org/10.1016/j.mpaic.2017.05.009

38.Greenwood JE: The evolution of acute burn care - retiring the split skin graft. Ann R Coll Surg Engl 2017, 99(6):432-438. https://doi.org/10.1308/rcsann.2017.0110

39. Gallagher G, Rae CP, Kinsella J: Treatment of pain in severe burns. American journal of clinical dermatology 2000, 1(6):329335. https://doi.org/10.2165/00128071-200001060-00001

40. Griggs C, Goverman J, Bittner EA, Levi B: Sedation and Pain Management in Burn Patients. Clin Plast Surg 2017, 44(3):535540. https://doi.org/10.1016/j.cps.2017.02.026

41.Lynn SJ, Cardena E: Hypnosis and the treatment of posttraumatic conditions: an evidence-based approach. The International journal of clinical and experimental hypnosis 2007, 55(2):167188. https://doi.org/10.1080/00207140601177905 